
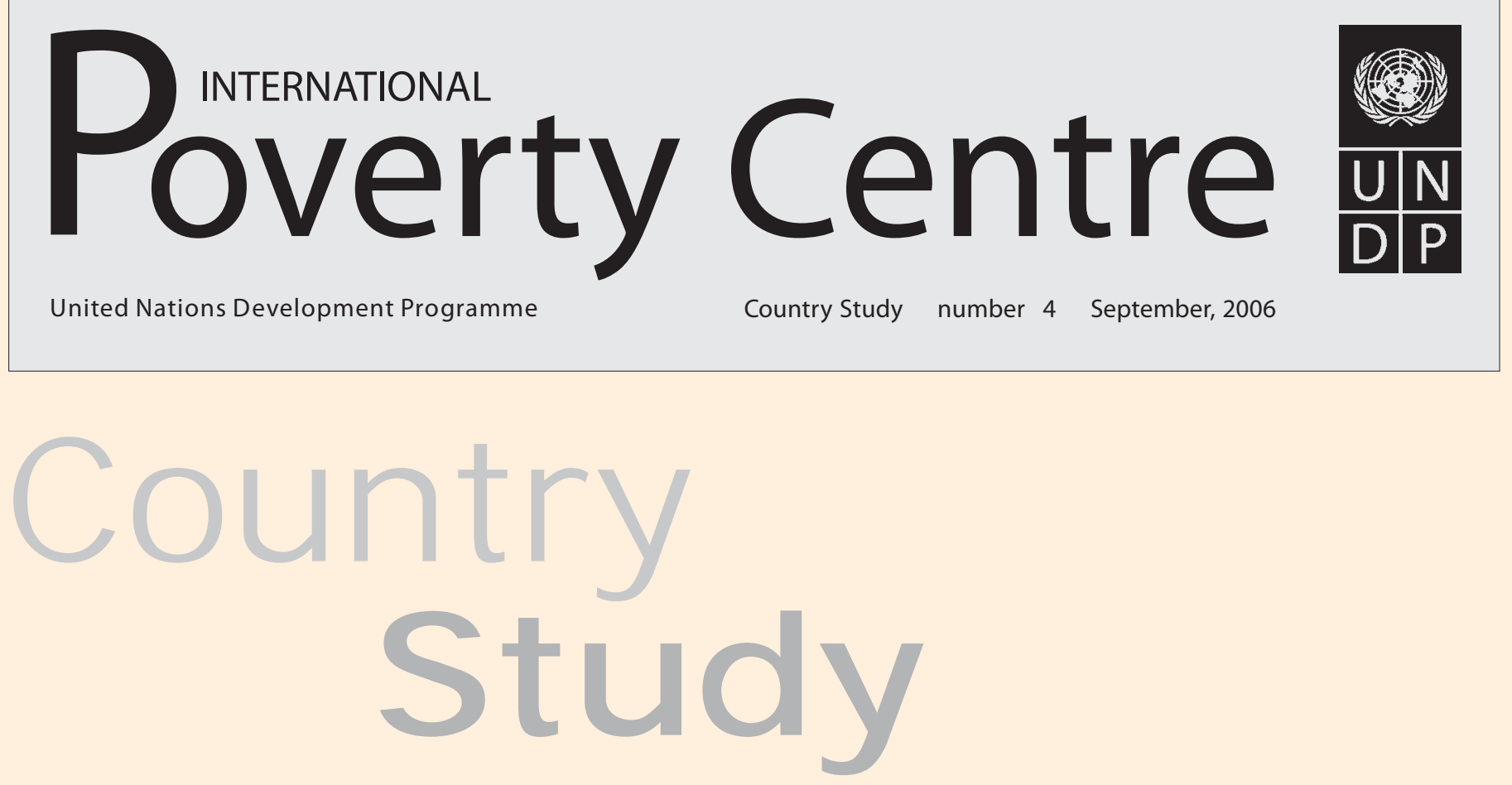

\title{
STRENGTHENING THE EMPLOYMENT \\ IMPACT OF AN MDG-BASED DEVELOPMENT STRATEGY FOR YEMEN
}

Country Study published by IPC, $n^{\circ} 4$

Terry McKinley

Senior Researcher and Acting Director, International Poverty Centre, United Nations Development Programme

and

Farhad Mehran

Statistical Development and Analysis, Policy Integration Department, International Labour Office 


\title{
Copyright $(\subset) 2006$
}

United Nations Development Programme International Poverty Centre

\author{
International Poverty Centre \\ $\mathrm{SBS}-\mathrm{Ed}$. BNDES, $10^{\circ}$ andar \\ 70076900 Brasilia DF \\ Brazil
}

povertycentre@undp-povertycentre.org

www.undp.org/povertycentre

Telephone +55 6121055000

Fax +55612105 5001

\section{Rights and Permissions}

All rights reserved.

The text and data in this publication may be reproduced as long as the source is cited. Reproductions for commercial purposes are forbidden.

The International Poverty Centre disseminates these Country Studies to encourage the exchange of ideas about development issues. These studies are signed by the authors and should be cited standard accordingly. The findings, interpretations, and conclusions that they express are those of the authors. They do not necessarily represent the views of the International Poverty Centre or the United Nations Development Programme, its Administrator, Directors, or the countries they represent.

Country Studies are available online at http://www.undp.org/povertycentre and subscriptions can be requested by email to povertycentre@undp-povertycentre.org 


\title{
STRENGTHENING THE EMPLOYMENT IMPACT OF AN MDG-BASED DEVELOPMENT STRATEGY FOR YEMEN
}

\author{
Terry McKinley and Farhad Mehran*
}

This Country Study seeks to identify employment policies for Yemen that would support an ambitious MDG-based Development Strategy. Based principally on Labour Force and Labour Demand Surveys, it analyzes Yemen's labour force, structure of employment and unemployment, demand for labour, and hours and wages. The study shows that the country is caught in a scissors between slow economic growth and rapid growth of the labour force. The result is widespread underemployment and poverty. While Yemen currently enjoys a boon in oil revenues, its economy remains undiversified and suffers from low productivity and incomes. As a result, the Country Study proposes a four-pronged MDG-oriented Growth, Employment and Poverty Reduction Strategy that would help the country reach the MDGs. This strategy is designed to accelerate economic growth, improve the employment intensity of growth, focus more resources on the poor and stimulate private-sector expansion, particularly in sectors with strong potential for growth and employment.

\footnotetext{
* Respectively, Senior Researcher and Acting Director of the International Poverty Centre, Brasilia, and staff member, Statistical Development and Analysis, Policy Integration Department, the International Labour Office, Geneva.
} 


\section{INTRODUCTION}

This Country Study draws on a much longer UNDP-supported report, Macroeconomic Policies for Poverty Reduction: the Case of Yemen (Karshenas et al. 2006) in order to closely examine the employment implications of formulating an MDG-based development strategy for the country. Based on the analysis of available data on employment, the study proposes a four-pronged strategy that will strengthen the employment basis for Yemen's achievement of the Millennium Development Goals. Yemen's success in doing so will depend on both accelerating growth and making it more employment intensive.

Recent economic growth has been moderate in Yemen, i.e., about five per cent per year, between 1995 and 2003. But the rate of growth of income per person has been much lower, namely, 1.5 per cent, because of the rapid growth of population in the country. Much of the economic growth has been powered by the increase in oil production, which has risen to account for about one third of GDP. While oil production has contributed to increasing exports and public revenue, it has not stimulated broad-based growth throughout the Yemeni economy.

One result of such narrowly based growth is the lack of employment creation. Yemen is caught in a scissors - between slow economic growth and continuing rapid growth of its population, especially its labour force. As new workers enter the labour force, they find few opportunities for remunerative employment. Either they remain unemployed or they push older workers out of formal employment. If formal-sector jobs, either public or private, are not available, then they opt for low-paying and irregular informal-sector employment.

Compounding the problem is a rising participation rate of female workers, who join the labour force, in most cases, because they have to counteract declines in real household income.

The employment problems that Yemen faces are similar to those in many other countries in the Middle East and North Africa. The countries of this region will have to create 80 million more jobs by 2020 just to absorb new entrants into the labour force. If they want to reduce unemployment, which averages about 15 per cent in the region, they will have to create 100 million more jobs-a doubling of the current level of employment (World Bank 2003, p. 1).

While the public sector has accounted for much of formal-sector employment in this region in the past, it can no longer provide decent-paying jobs to a rapidly growing labour force. The private sector needs to provide employment to a larger share of the labour force. But the public sector has to continue playing a central role by financing public investment to provide essential social and economic services, without which the private sector would languish. The public sector can also help by supporting and encouraging the banking sector to provide more loans to stimulate productive private investment.

While Yemen is similar in many ways to other countries in the region, it also has distinct problems, stemming from its low level of development. Yemen is a Least Developed Country, with a low level of income per person and human development. It remains heavily dependent on agriculture, and on oil. Its economy is undiversified and under-developed. One barometer of this under-development is the small size of its manufacturing sector. Confronted with such initial conditions, Yemen must find new sources of growth and diversify its economy, not only wtihin manufacturing but also within agriculture and services. Only as growth accelerates and expands in sectors with higher labour productivity will the economy be able, ultimately, to generate widespread employment at decent wages. 


\section{TRENDS IN THE LABOUR FORCE}

Yemen's rapid rate of population growth is exerting tremendous pressure on the labour market to create jobs. At about 3.5 per cent growth per year, this rate is one of the highest in the world. Between 1990 and 2000 alone, Yemen's population expanded by fifty per centnamely, from 12.8 million to 18.4 million. As a result, the age group 15 years of age or younger accounts for almost half of the population. The median age is projected to increase to only 16.6 years by 2020 so the Yemeni population will remain disproportionately young for a long time.

By 2000 the ratio of dependants to workers was approaching five to one-an unsustainably high level. This intensifies the need for each person of working age to secure decent-paying employment. Moreover, as increasing numbers of the young reach working age, many more jobs are needed each year to employ them. However, the growth of employment lags well behind the growth of the labour force. Consequently, underemployment and poverty remain persistently high. And open unemployment is rising: workers holding out for decent wages cannot find employment.

Slackening demand for Yemeni workers in other countries in the region has compounded the employment problem. Slow economic growth in these countries-especially in constructionis part of the explanation. Increased competition with nationals as well as cheaper foreign workers, such as from South Asia, is another part. Nevertheless, the number of Yemenis working abroad remains high. One estimate is that they represent about one quarter of the total Yemeni labour force (working both at home and abroad). In 1998, for example, they were estimated to number over one million workers. Their remittances, although falling since the early 1990s, still add up to almost one fifth of GDP. Thus, their earnings are essential to the livelihoods of many Yemeni households-as well as improving the current-account balance. Yet, the fact that these workers have to work abroad is an additional testament to the slow growth of employment within the country.

Between 1995 and 2000, the Yemeni economy grew by over six per cent per annum. Despite such growth, labour force participation rates and employment stagnated. The labour force participation rate declined from 45.8 per cent in 1994 to 44.3 per cent in 1999 (based on defining labour force participation for the 1999 Labour Force Survey in the same way that it is defined for the 1994 Population Census) (Table 1). This is explained by the decline in the participation rate of men of working age from 74.1 per cent to 67.8 per cent. Conversely, the participation rate of women rose from almost 17 per cent to almost 21 per cent. But this rate is explained mostly by women's increased participation in rural areas. In urban areas, their participation rate is still only 10.4 per cent.

These statistics suggest that the average annual growth rate of the labour force is 3.8 per cent. But the growth rate for women is 5.3 per cent while that for men is 3.3 per cent. Men have been dropping out of the labour force while women have been joining it.

The trends for employment mirror those for labour force participation. Between 1994 and 1999, the ratio of the employed to the working age population edged down from 42 per cent to 40.6 per cent (Table 1). Since Population Censuses tend to under-estimate employment, the drop during these years was probably sharper. The employment-population ratio for men dropped from 67.2 per cent to 61.2 per cent while that for women rose from 16.2 per cent to 20.0 per cent. While the economy was growing, this growth was not being translated into decent-paying employment, and certainly not for male workers. Women were finding jobs, but 
primarily in order to offset the loss of income due to male unemployment or underemployment. The jobs that women secured were low paying or in unpaid household activities. Much of their employment remained in agriculture.

TABLE 1

Labour Force Participation, 1994-1999 (\%)

\begin{tabular}{|c|c|c|}
\hline \multirow{2}{*}{ Labour Force Participation Rate } & Population Census & Labour Force Survey \\
& 1994 & 4999 \\
\hline Total & 45.8 & 67.8 \\
\hline Male & 74.1 & 20.9 \\
\hline Female & 16.9 & 1999 \\
\hline \multirow{2}{*}{ Employment-Population Ratio } & Population Census & 40.6 \\
\hline Total & 1994 & 61.2 \\
\hline Male & 42.0 & 20.0 \\
\hline Female & 67.2 & Labour Force Survey \\
\hline
\end{tabular}

Sources: Mehran 2004c, based on the 1994 Population Census and 1999 Labour Force Survey.

The only age group among men for which the employment-population ratio rose between 1994 and 1999 was that between 15 and 19 years of age (Mehran 2001). The decline in this ratio was particularly severe among workers 45 years of age and older. This decline was worse for workers 55-59 years of age and worse still for workers 60-64 years of age. As job creation stagnated, older workers found themselves at a distinct disadvantage in the labour market. Among women, the employment-population ratio increased most dramatically among the age group that was 25-49 years of age, and particularly among women 35-49 years of age. Among women 50 years of age or older, the ratio stagnated or declined.

Between 1994 and 1999, the percentage of the employed earning wages or salaries stayed about the same, at about 41.5 per cent of the total (Mehran 2004c). However, the percentage of workers in self-employment declined from about 39 per cent to about 33 per cent while the percentage of workers in unpaid household activities rose from about 19 per cent to about 25 per cent. The rise of unpaid work highlights the underlying stagnation of employment generation. Employment 'opportunities' have been expanding mainly in small family enterprises, most of which have been in agriculture.

\section{THE STRUCTURE OF EMPLOYMENT}

The structure of employment in Yemen illustrates why the country is having difficulty in generating widespread employment that pays decent wages. Agriculture accounted for about 54 per cent of all employment in 1999 (Table 2). Industry is particularly weak: it accounted for less than five per cent of employment in 1999-a woefully low percentage. Accounting for 6.6 per cent, construction provided more employment than industry.

Even more important was trade, which provided over 12 per cent of employment. More important still was transport, accounting for almost 18 per cent. The remainder of jobs were provided by services (other than trade and transport). So the Yemeni economy exhibits some degree of diversification but its industrial sector is remarkably small, reflecting the inability of the economy to raise productivity and real wages. An additional problem is that during 2001-2003 
labour productivity basically stagnated in manufacturing. For example, while value added per worker was 210,000 Rials in 2001, it was the same in 2002 and had increased to only 220,000 Rials in 2003.

TABLE 2

Sectoral Structure of Employment (\%) 1999

\begin{tabular}{|l|c|c|c|}
\hline Sector & Total & Male & Female \\
\hline Agriculture & 54.1 & 43.1 & 87.8 \\
\hline Industry & 4.6 & 5.1 & 2.8 \\
\hline Construction & 6.6 & 8.7 & 0.2 \\
\hline Trade & 12.1 & 15.5 & 1.4 \\
\hline Transport & 17.7 & 21.2 & 7.0 \\
\hline Other Services & 19.3 & 23.1 & 7.7 \\
\hline
\end{tabular}

Source: Labour Force Survey 1999.

As in many other countries in the Middle East and North Africa, men hold the great majority of jobs, i.e., about three quarters. Also, half of the male workers have paid employment. In contrast, only about 14 per cent of female workers have secured such employment.

Still, about 43 per cent of male workers are employed in agriculture whereas only about five per cent are employed in industry (Table 2). However, almost 88 per cent of female workers are in agriculture. And of all female workers, over 62 per cent are in unpaid work. In contrast, only a little more than 13 per cent of male workers are in unpaid work. So there are stark gender imbalances in employment in Yemen. However, women are joining the labour force in growing numbers. This trend adds another powerful factor-in addition to the rapid increase of young workers and the large continuing stock of workers already unemployed or underemployed - that necessitates an acceleration in employment creation.

Part of the explanation for these gender trends in employment is the lack of dynamism in both industry and services in Yemen. The share of the employed in public administration dropped from over 13 per cent in 1994 to a little under 10 per cent in 1999 (Mehran 2004c). This decline affected mostly male workers. The slow growth of private-sector services could not compensate for the loss of public-sector services. Overall, the share of employment in services dwindled from 36.5 per cent to 34.8 per cent. This is an unusual trend. Since the share of employment in industry stayed virtually the same, agriculture had to take up the slack, boosting its share from 52.2 per cent to 54.1 per cent. It is in this sector that female workers increased their employment.

\section{TRENDS IN UNEMPLOYMENT}

As an indicator, unemployment gives limited information on the labour market in developing countries. It is particularly limited for gauging the condition of poor workers, who usually cannot afford to be unemployed for long. It also does not reveal how many workers have simply dropped out of the labour force, because of discouragement or their default involvement in the informal sector. It does, however, provide useful information on the extent to which an economy can provide employment that is appropriate for more skilled or educated workers, i.e., those who can usually afford to wait for a job that is commensurate with their abilities. 
Despite a decline in the employment-population ratio between 1994 and 1999, open unemployment remained at about 8.4 per cent. This signifies that many workers were simply dropping out of the formal sector, and thus were not showing up on the employment rolls. While male unemployment stood at 9.7 per cent in 1999, female unemployment stood much lower, at 4.2 per cent.

If statistics incorporate a broader definition of unemployment (including people who are available for work but are not seeking it), then the unemployment rate rises to 11.5 per cent in 1999, with male unemployment rising to 12.5 per cent and female to 8.2 per cent (see Mehran 2004b). While giving a broader view of the state of unemployment in 1999, these statistics are not comparable to those from the 1994 census. Moreover, they might be misleading in the sense of over-estimating the problem of unemployment and correspondingly downplaying the importance of underemployment-the condition of most poor workers in Yemen.

Despite the stability in the overall unemployment rate, the youth unemployment rate (based on a strict definition for workers 15-24 years of age) declined significantly, i.e., from 17.9 per cent in 1994 to 12.7 per cent in 1999. This is indeed a hopeful sign. This statistic is also consistent with the rise in the percentage of the employed who are educated (have a secondary school education or above), from 10.6 per cent in 1994 to 15.7 per cent in 1999. Younger workers who are securing jobs tend to be more educated than older workers.

At the same time, however, the unemployment rate among educated youth remains high, at about 23 per cent. Broadening the definition of unemployment reveals that the percentage of youth who are inactive (neither in the labour force nor in school) is about one third. But this is due mainly to 'inactivity' among young women, many of whom are likely engaged in unrecorded household work. The 'inactivity' rate among young women in 1999 was over 60 per cent. Hence, despite improvements in employment outcomes, such as the drop in youth unemployment, overall employment generation in Yemen remains lackluster.

Projections based on data from the 1999 Labour Force Survey on the growth rate of employment vis-à-vis that of the labour force suggest that while the unemployment rate was 11.5 per cent in 1999 (according to a broad definition of unemployment), it could rise to 17.1 per cent in 2006. Civilian employment could reach about 4.402 million workers while the labour force could reach 5.31 million (Mehran 2004a) - a shortfall of 908,000 jobs. At the same time, while youth unemployment (based on the broad definition) was 18.7 per cent in 1999, under these projections it could balloon to an incredibly high 34 per cent.

If the labour force continues to grow at 3.8 per cent a year (higher than the growth rate of the population), then jobs need to be created for an additional 188,000 workers every yearjust to keep unemployment constant (Mehran 2004a based on statistics from the Ministry of Planning). This could be decomposed into 121,000 jobs for men (if the male labour force is growing at 3.3 per cent) and 67,000 jobs for women (if the female labour force is growing at 5.3 per cent).

If, in addition, the unemployment rate were to be reduced by one percentage point each year, then 22,000 more jobs would need to be created annually. Added to the 188,000 jobs needed every year (just to keep unemployment constant), the total would be 210,000 new jobs every year. Such a scale of job creation is beyond the current capacity of the Yemeni economy to generate. Growth would have to be not only more rapid but also more employment-intensive. 


\section{THE DEMAND FOR LABOUR}

Based on 2002-2003 trends, labour demand is currently increasing by about 117,000 paid jobs per year. This is an annual growth rate of 2.8 per cent. This rate implies that there will be an excess supply of labour of 71,000 every year (Mehran 2004a). Since the public sector has had to act as 'the employer of last resort', it has only modest capacity to create new jobs. Public administration has been, in fact, in relative decline. Hence, the private sector has to become dynamic enough to generate an additional 71,000 jobs every year, just to keep unemployment in check.

The Labour Demand Survey of 2002-2003 gives us an initial picture of the private sector's capacity to create decent jobs. The survey is limited in scope: it covers private-sector establishments, which account for only about 18 per cent of total civilian employment. Government employment accounts roughly for another 20 per cent. Agriculture accounts for about 50 per cent. The residual percentage (about 10 per cent) is mostly self-employment or casual employment in non-agricultural activities.

Much of the employment in private-sector establishments is self-employment or unpaid work. Paid employment accounts for only 37 per cent of the total. Paid employment in establishments accounts for a minority share of the sector's employment; and private-sector establishments account, as a whole, for a modest share of total employment. Nevertheless, the capacity of the Yemeni economy to generate much more poverty-reducing employment hinges on the growth of paid employment in private-sector establishments.

Unfortunately, the birth rate of such establishments is low: only about four per cent of all establishments are new each year (Mehran 2004a). And these establishments are invariably micro enterprises, providing employment mostly for owner-managers and secondarily for unpaid members of the manager's household. There are only 2.5 paid employees for every 100 establishments. Hence, despite the widespread donor romanticism with regard to micro enterprises, they obviously offer, by themselves, only a negligible part of the solution to unemployment, or underemployment for that matter.

During the period of coverage of the Labour Demand Survey (April 2002 - May 2003), the establishment sector created 19,379 paid jobs. Only about half of these jobs could be considered new since the other half were technically replacement jobs. At the same time, 37,272 paid jobs were eliminated. Hence, there was a net decline of 17,893 paid jobs, representing a 5.7 per cent decline, during this year.

The largest losses of paid jobs, in absolute numbers, were in three sectors: trade $(-12,836)$, manufacturing $(-1,907)$ and hotels and restaurants $(-513)$ (Table 3$)$. Manufacturing and trade are the largest sources of paid employment: the former accounts for over 96,000 paid jobs while the latter provides almost 70,000. Trade experienced the largest percentage loss in paid employment, i.e., -18.5 per cent. If paid employment is going to expand, these three critically important sectors have to flourish.

Net gains in paid employment occurred only in education $(+448)$, farming $(+256)$ and mining (+129). Farming had the largest percentage increase, namely, 4.4 per cent. Both mining and education provide significant numbers of paid jobs, but farming does not.

If the data on employment trends from the Labour Demand Survey are accurate (see Table 4), then the widespread preconception that micro enterprises (defined as employing 1-4 workers) 
and small enterprises (5-9 workers) are the primary engine of job creation in Yemen is false. Both micro and small enterprises recorded net job losses during the survey period whereas both medium-sized enterprises (10-19 workers) and large enterprises (20+ workers) recorded net job gains (Table 4).

TABLE 3

Gains and Losses in Paid Jobs by Economic Sector, 2002-2003

\begin{tabular}{|l|c|c|c|}
\hline Sector & Paid Employees & Net Change of Jobs & Percentage Change \\
\hline Farming & 5,786 & +256 & 4.4 \\
\hline Mining & 10,348 & +129 & 1.2 \\
\hline Manufacturing & 96,385 & $-1,907$ & -2.0 \\
\hline Trade & 69,359 & $-12,863$ & -18.5 \\
\hline Hotels/Restaurants & 25,786 & -513 & -2.0 \\
\hline Transport & 7,767 & -110 & -1.4 \\
\hline Education & 9,637 & +448 & 4.6 \\
\hline Health & 11,119 & -110 & -1.0 \\
\hline Personal Services & 9,192 & -201 & -2.2 \\
\hline
\end{tabular}

Source: Mehran 2004a based on the Labour Demand Survey 2002-2003 (CSO and LMIS).

Note: Only sectors with more than 5,000 paid employees are included in this table.

Micro enterprises do account for a substantial number of paid employees, namely, over 88,000 but they experienced the largest net job losses of $-17,379$ (Table 4). This represented almost a 20 per cent decline. Paid employment in small enterprises declined by 2.5 per cent. At the other pole, large enterprises account for the biggest number of paid employees, namely, almost 108,000, and scored the biggest net job gains, i.e., 2,832. In medium-sized enterprises, employment rose by over four per cent.

Such data, limited and superficial though they are, suggest that medium-sized and large enterprises are likely to have the most potential to generate paid employment. Not noted by these data is the likelihood that these enterprises also provide decent-paying employment. Micro and small enterprises are much more likely to provide low, 'poverty-reproducing' wages. As one indication, about two-thirds of educated employees (with a university degree or specialized vocational training) are employed by large firms. Their wages are 20 per cent above the average for all educated employees. In small and medium enterprises, educated workers receive wages that are two-thirds of the average while in micro-enterprises they receive 56 per cent of the average.

TABLE 4

Gains and Losses in Paid Jobs by Establishment Size, 2002-2003

\begin{tabular}{|l|c|c|c|}
\hline Size of Firm & Paid Employees & Net Change & Percentage Change \\
\hline $1-4$ workers & 88,384 & $-17,379$ & -19.7 \\
\hline $5-9$ workers & 38,913 & -981 & -2.5 \\
\hline $10-19$ workers & 22,813 & 927 & 4.1 \\
\hline $20+$ workers & 107,798 & 2,832 & 2.6 \\
\hline Total & 257,908 & $-14,601$ & -5.7 \\
\hline
\end{tabular}

Source: Mehran 2004a based on the Labour Demand Survey 2002-2003 (CSO and LMIS). 


\section{MICRO AND SMALL ENTERPRISES}

Although various surveys in Yemen have investigated micro, small and medium-sized enterprises (MSMEs), their results are difficult to compare because they utilize different definitions of the size of each type of establishment. These surveys invariably estimate that micro and small enterprises employ most labour. But most of this employment is self-employment (i.e., owner-workers). Among micro-enterprises employing 1-4 workers, 61 per cent employ only one worker and another 20 per cent employ only two. Moreover, among small enterprises employing 5-9 workers, 44 per cent of the jobs are in firms with 5 workers and another 25 per cent are in firms with 6 workers. If micro and small firms are lumped together, those employing only one worker account for 59 per cent of all jobs and those employing only two workers account for another 19 per cent. So, firms in Yemen are very small on average.

While micro, small and medium-sized enterprises account for much of the employment in Yemen, their aggregate contribution to GDP is small. One estimate ascribes about seven per cent of GDP to MSMEs (Micro, Small and Medium Enterprises) (ILO 2004 based on the MSE Baseline Survey). Since the contribution of MSMEs is far lower than their contribution to employment, their level of labour productivity is pitifully small. Most of the workers in such firms are uneducated and unskilled. Hence, while more vibrant growth among micro, small and medium-sized enterprises might help to reduce poverty, its overall effect is not likely to be pronounced since incomes in such enterprises tend to be meagre. The exception is likely to be medium-sized firms, which public policy often neglects. Government policies are often biased towards large enterprises while poverty reduction strategies often focus their attention on micro and small enterprises. In order to correct these biases, the Government should develop a more comprehensive economic strategy that can integrate the contributions of micro and small enterprises, medium-sized enterprises and large enterprises.

The Government of Yemen can do more to create a conductive business environment that can allow micro and small enterprises to flourish. But if its medium-term objective is to generate widespread employment at poverty-reducing wages, it must find ways to encourage growth among medium-sized and large enterprises. In manufacturing, for example, mediumsized enterprises tend to be concentrated among subsectors such as paper and printing, and machines and equipment. Large manufacturing firms are concentrated in subsectors such as chemicals and plastics, and oil refining. While medium-sized firms account for seven per cent of total manufacturing employment, large firms account for 36 per cent (ILO 2004, pp. 38-39).

Surveys reveal that some of the main problems confronting micro, small and mediumsized enterprises are stagnation of their product markets, lack of reliable electricity and other economic services and lack of financial resources (ILO 2004, pp. 47-49). Stagnation is due mainly to lack of economic growth. While the government can contribute to generating more growth by reducing excessive regulations and making business taxes more equitable, it can play a more pro-active role in undertaking public investment to expand access to economic and social services, such as electricity, water, health and education. It can also help in expanding access of businesses to financial services or providing training facilities for developing management skills and technical advice for starting up businesses.

\section{EXPECTED JOBS GAINS}

In addition to determining the scale of net job losses or gains for the period 2002-2003, the Labour Demand Survey also inquired about prospects for losses or gains during 2004-2006. 
Since the results reflect the expectations of establishments, they are obviously less reliable than their reports on past results. Nonetheless, the results are intriguing.

While the establishments report an aggregate net job loss of 5.7 per cent during 2002-2003, they project a net gain of 5.4 per cent for 2004-2006. The biggest absolute gains are expected in trade $(+18,307)$ and manufacturing $(+9,289)$. Together, these two sectors account for about 62 per cent of the total projected increase. The biggest percentage increases are projected in health (+12.4 per cent), personal services (+12.0 per cent) and education (+8.2 per cent). But these three sectors account for about one quarter of the total projected absolute increase in paid employment. The hotel and restaurant sector and the mining sector project growth at only a 1-2 per cent rate.

Micro enterprises are optimistic about projected increases in paid employment: they project an increase in net labour demand of 7.3 per cent (about 21,000 jobs). But the most optimistic are medium-sized enterprises, which project a net job increase of almost 10 per cent (about 7,500 jobs). Large enterprises project a bigger absolute increase in jobs (about 9,400) but a much smaller percentage increase, i.e., less than three per cent.

In total, establishments project a net increase of 44,468 jobs over the three years of 20042006. This translates into 14,800 new jobs a year. Even if these optimistic projections are confirmed, the net yearly increase in labour demand of 14,800 would still be only a small share of the net yearly increase of 71,000 that is needed. Unless more dynamic sources of growth and employment generation are identified and then actively promoted, unemployment is sure to rise-as is underemployment, spreading principally in the informal sector.

\section{TRENDS IN HOURS AND WAGES}

One indication of the low-paid nature of much of the employment in Yemen is that many workers have to labour in excess of forty hours a week in order to obtain subsistence-level incomes. This is particularly true for male workers. The average for employed males in their primary jobs is 40 hours a week but over one third of them have to work 48 hours or more. ${ }^{1}$ Over 15 per cent of female workers also have to work 48 hours or more. Thus, almost 30 per cent of all the employed work such hours.

Another reflection of the low pay of jobs in Yemen is that many workers also cannot secure enough hours of work per week. About 40 per cent of all the employed labour less than 35 hours a week, with 8.5 per cent of them labouring less than 15 hours. While men tend to work excessive hours, women have greater problems securing enough hours. Almost 55 per cent of female workers labour less than 35 hours a week, with almost 12 per cent of them labouring less than 15 hours.

A major reason for this pattern is that women are concentrated in sectors, such as services and agriculture, which provide irregular employment. Fifty-five per cent of women in paid employment are in services, where their average weekly hours are 31 . Another 36 per cent are in agriculture, where their average weekly hours are 32. By contrast, men are more concentrated in industry and trade, where average hours tend to be high: the average is 45 hours in industry and 50 in trade. This bimodal distribution of hours of work, reflecting to some degree gender differences, implies that jobs offering a reasonable number of hours (in the range of 35 to 47 hours a week) are scarce. Only about 28 per cent of all employed workers have jobs with this range of weekly hours. 
Growth in micro and small enterprises is not likely, by itself, to resolve this problem. Their employment is often self, casual or unpaid employment, not regular paid employment. Over the long term, the expansion of paid employment in medium-sized and large enterprises is more likely to 'regularize' hours of work, i.e., stabilize them within a reasonable range that can provide decent levels of income.

Despite economic growth in Yemen, real wages declined in the late 1990s. Part of the reason was the removal of subsidies on energy, transport and food, which raised prices and the overall cost of living for workers. Nominal wages were increased in the 1990s in both the public and private sectors, but these increases were far outstripped by price increases. While the minimum wage rate in nominal terms had risen, for example, to about US\$ 40 per month in 1998, the real value of this wage was only 30 per cent of its 1990 level (ILO 2004).

One measure of the working poor is that about 13 per cent of paid employees in Yemen in 1999 earned wages that were lower than the Food Poverty Line (as defined by the Family Budget Survey). In addition, about 39 per cent of paid employees earned wages that were lower than the overall Poverty Line (defined on the basis of food and non-food needs). Assuming that the methodology for establishing these poverty lines is sound, such a measure of the working poor would be more useful than unemployment. Employment outcomes should be judged, for example, by whether they decrease the percentage of workers who earn wages lower than the overall poverty line.

Among paid employees, there are significant wage differentials by sector. The differential in average weekly wages between the private sector and the public sector has widened, for example. Whereas public-sector wages used to be comparable to private-sector (and mixedsector) wages, now they have fallen to about one third of the private-sector level. Such low wages tend to undermine the capacity of the public sector.

Part of the differential in total weekly wages is due to differences in the number of hours worked. Monthly average earnings in agriculture are low, for example, because hours per week are not only below average ( 39 hours) but (and more importantly) hourly earnings are also very low ( 65 Rls per hour) (Table 5$)$. In services, hourly earnings are near average (73 Rls per hour) but hours worked per week ( 37 hours) are the lowest of any sector. In trade, however, hourly earnings are low (66 Rls per hour) but earnings are boosted by above-average hours worked per week (50 hours).

On an hourly basis, average earnings for all sectors are 76 Rls (Table 5). Earnings in construction are the highest, at 106 Rls per hour. Earnings in transport are also relatively high, at 95 Rls per hour. By contrast, earnings are lowest in agriculture (65 Rls per hour) and trade (66 Rls per hour). Earnings in industry and services are closer to the average.

In most sectors, women who are paid employees have average hourly earnings that are higher than those for men. This is the case, for example, in industry, construction, trade and services. The one sector in which women's hourly earnings (64 Rls per hour) are lower than men's is agriculture. The major problem is that in all sectors women are a minority of paid employees. In addition, they work far fewer hours. On an hourly basis, the earnings of women (76 Rls) are slightly higher than those of men (75 Rls). On a monthly basis, however, women earn only 10,400 Rls compared to 13,299 Rials for men. This is due to fewer work hours.

Wage inequality is a problem in Yemen. But it is not due necessarily to inequality in educational attainment. While the highest-paid five per cent of employees earn 50,000 Rials 
per month, the lowest-paid five per cent earn 5,000 Rials. Thus, the ratio of earnings of the top five per cent to the bottom five per cent is 10 to 1 . Workers with higher education are more concentrated, as expected, among those who earn 50,000 Rials or more while illiterate workers are more concentrated among those who earn less than 5,000.

TABLE 5

Hours and Earnings by Sector, 1999

\begin{tabular}{|l|c|c|c|c|}
\hline Economic Sector & $\begin{array}{c}\text { Percentage of } \\
\text { Total Paid } \\
\text { Employees }\end{array}$ & $\begin{array}{c}\text { Average Weekly } \\
\text { Hours }\end{array}$ & $\begin{array}{c}\text { Average Monthly } \\
\text { Earnings (RIs) }\end{array}$ & $\begin{array}{c}\text { Average Hourly } \\
\text { Earnings (RIs) }\end{array}$ \\
\hline Total & 100 & 40 & 13,000 & 76 \\
\hline Agriculture & 20.6 & 39 & 10,800 & 65 \\
\hline Industry & 7.0 & 45 & 13,700 & 71 \\
\hline Construction & 14.2 & 41 & 18,600 & 106 \\
\hline Trade & 10.0 & 50 & 14,100 & 66 \\
\hline Transport & 3.5 & 41 & 16,600 & 73 \\
\hline Other Services & 44.7 & 37 & 11,500 & 75 \\
\hline
\end{tabular}

Source: Mehran 2001 based on the 1999 Labour Force Survey.

But the relationship between education and earnings is not monotonic. In the earnings range of 10,000 to 20,000 Rials per month, for example, workers with higher education are heavily concentrated. About half of government employees are concentrated in this earnings range. Also, among paid employees with earnings in the higher range of 20,000 to 50,000 Rials, illiterate workers are more concentrated than normal while workers with higher education are only slightly more concentrated than normal. Thus, the labour market in Yemen is not functioning well. There is lack of demand for educated workers. Many of them are concentrated in public-sector employment but at low wages.

\section{POLICY RECOMMENDATIONS}

In order to provide widespread remunerative employment, Yemen's economy needs to grow at a much more rapid rate and spread the benefits of growth more broadly among the population. This will necessitate a dramatic scaling-up of both public and private investment in support of a national development strategy that can enable the country to reach the MDG targets. Financing for such investment will have to come from various sources: oil revenue, increased tax revenue on non-oil incomes, the use of international reserves, debt relief and substantially increased ODA.

The Government of Yemen can pursue a four-part strategy to begin generating more rapid and more employment-intensive growth. The first prong is to begin implementing more growth-oriented economic policies. Various chapters of the full report (Karshenas et al. 2006) have detailed recommendations for fiscal, monetary and exchange-rate policies.

\section{MOBILIZING DOMESTIC RESOURCES FOR GROWTH}

A major priority is to expand fiscal space. This could be achieved, in part, by raising more revenue. This could be based on instituting a General Sales Tax, imposing an excise tax on petroleum, eliminating many custom exemptions, increasing the level of taxation of Qat and 
imposing a land tax on large farm holdings and a tax on urban real estate. In conjunction with improving tax collection, such measures could raise revenue by 6-9 percentage points of GDP.

On the expenditure side, fiscal space could be opened up by reducing military expenditures from seven per cent of GDP to four per cent and by phasing out explicit subsidies so as to earmark the resultant funds for priority investment, such as for improving agricultural productivity. The general objective should be to achieve a balance between revenue and expenditures at a level of 20-25 per cent of GDP.

While the Government enjoys the boon of increased oil revenues, it should re-orient fiscal policies in order to aggressively channel these revenues into financing widespread public investment in basic economic and social infrastructure. Such investment will not only advance human development (such as for greater health and education) but it will also give a boost to economic activity (through provision of basic infrastructure such as electricity, gas, water and roads).

The main purpose of significantly increasing Official Development Assistance to Yemen while it enjoys high oil revenues is to smooth its transition to a long-run position of reliance on diversified sources of domestic revenue, particularly since oil revenue is projected to eventually run out. In this respect, ODA could help Yemen reduce its current need to hold a large stock of resources in a surplus oil fund.

A crucial development variable for Yemen is the ratio of gross national savings to GDP since it indicates the country's ability to mobilize domestic resources for development. Figure 1 shows the recent decline in Yemen of both public and private gross national savings as a share of GDP. As a result, gross national savings has been falling since 1999.

FIGURE 1

Public, Private, and National Savings as per cent of National Disposable Income, 1995-2003

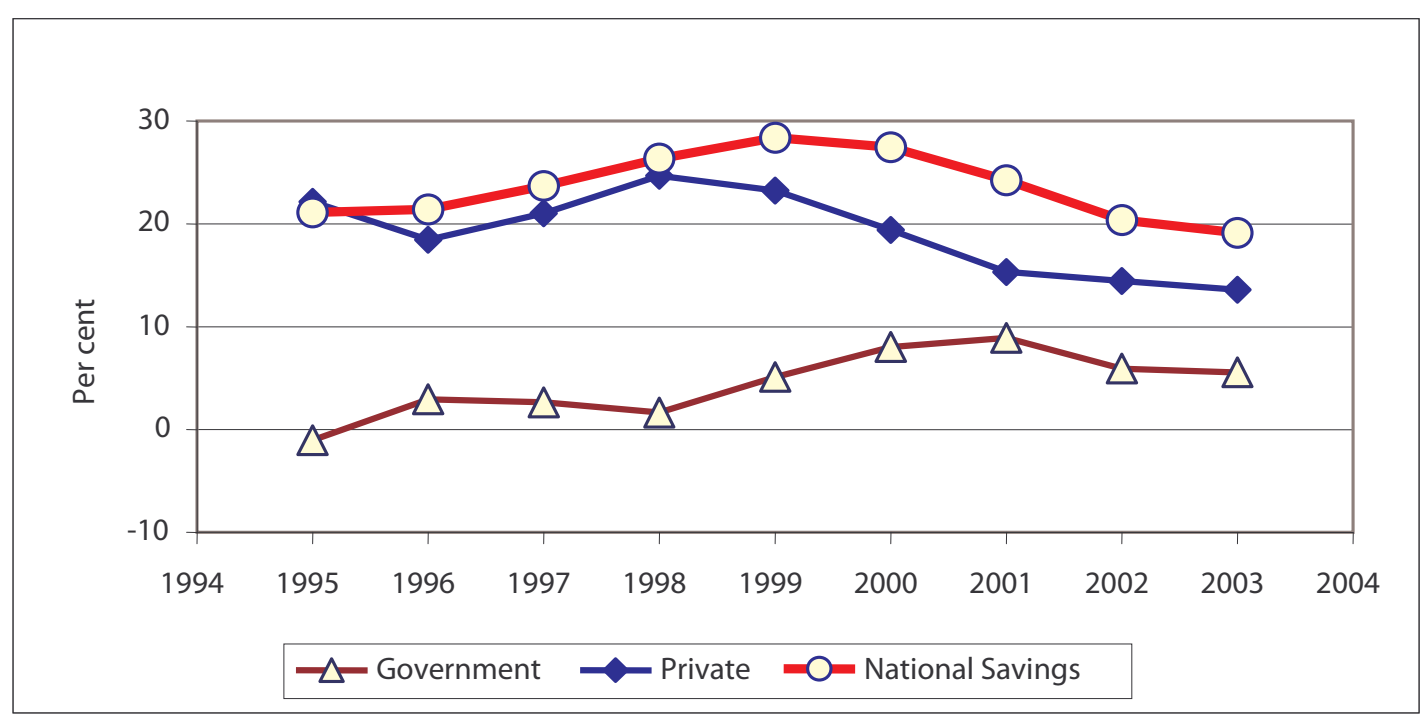

Notes: National disposable income includes curent transfers (mainly remittance income) from abroad. The data are two-year moving averages.

Source: Karshenas et al. 2006. 
The development and expansion of financial institutions are crucial to mobilizing development resources. Through various measures, the government should encourage banks to play a stronger intermediary role in mobilizing domestic savings and directing it to long-term productive private investment. For example, gross investment remains relatively low: in 2002 it was 17 per cent of GDP (World Bank 2004). While this is partly explained by a lack of stimulus from public investment, it is also explained by a poorly functioning financial system.

\section{MONETARY AND EXCHANGE-RATE POLICIES}

Monetary policies also need to be overhauled in order to establish employment creation as a Central Bank target in addition to moderate inflation (e.g., 5-15 per cent per year). Reducing the inflation rate below five per cent, as the International Monetary Fund often recommends, could plunge Yemen into a 'stabilization trap'. Instead of maintaining high real rates of interest (as a means to maintain low inflation), the Central Bank should seek to lower interest rates in order to stimulate more domestic investment.

Figure 2 shows that the main source of Yemen's inflation is rising food prices, especially since 2000. Thus, a useful short-run policy response to combat inflationary pressures would be to initiate a food price stabilization programme. This would help hold down real wages and contribute to Yemen's international competitiveness in non-oil exports. The longer-run solution is substantial investment in physical and human capital, which could boost the productivity of Yemen's economy, particularly in the agricultural sector, where low productivity and low incomes are the source of much of the country's poverty. The Central Bank could use its considerable holdings of foreign exchange reserves in order to set up a special discount window for banks that agree to lend for such investment purposes.

FIGURE 2

\section{Inflation Rates in the Food and Non-Food Components of CPI, 1998-2003}

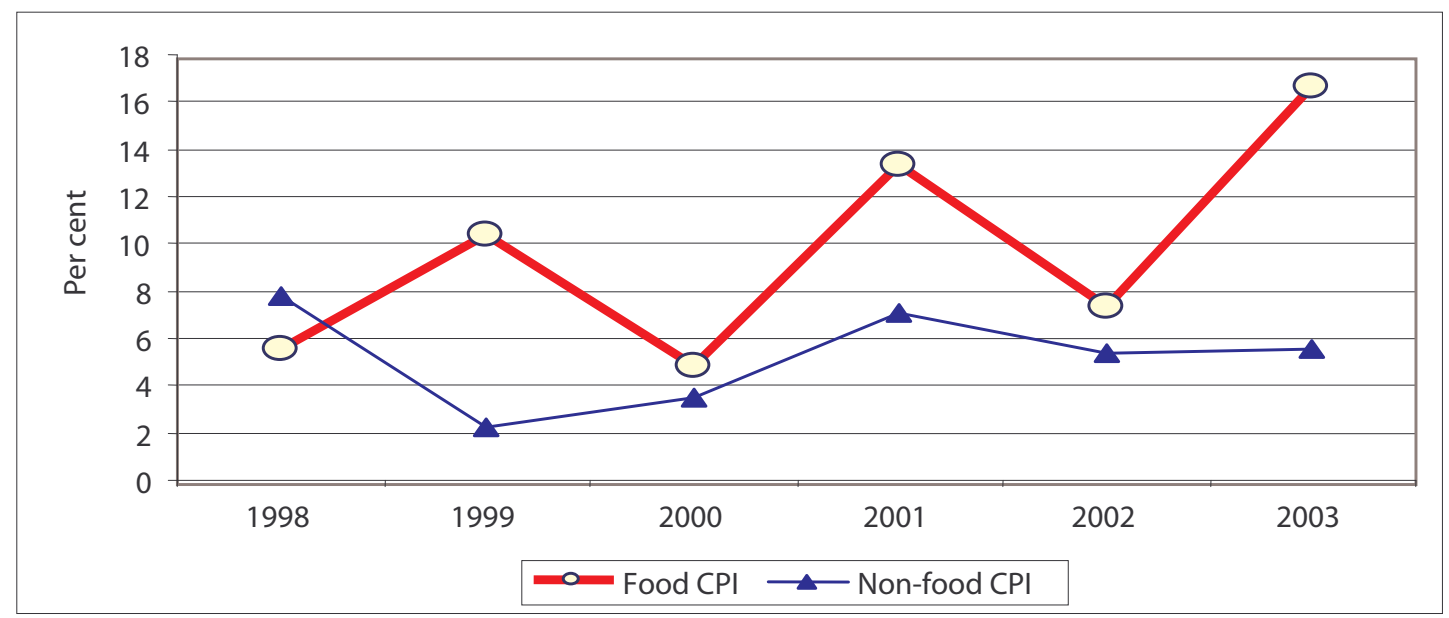

Notes: Both Indices exclude Qat and Tobacco. The Qat and Tobacco price index increased by 90 per cent during 2000-2003, showing the highest increase of all CPI components.

Source: Central Statistical Office, electronic file.

In order to maintain the international competitiveness of non-oil exports, the government should also move to depreciate the exchange rate. Such a measure should be combined with restrictions on capital mobility, particularly within the context of more expansionary fiscal and 
monetary policies. Appreciation of the exchange rate encourages capital outflows, which can rob Yemen of potential development resources. Hence, the Central Bank should regulate the capital account. A priority would be to restrict commercial banks from investing in financial assets abroad. This would help prevent the leakage of foreign exchange, generated by oil revenues or ODA, out of the economy.

\section{ALLOCATING RESOURCES TO PRIORITY SECTORS}

The second prong of the government's employment-creation strategy should be policies geared to diversifying the economy and supporting sectors with growth and employment potential. Targeted credit policies are part of this prong. For example, the Central Bank of Yemen could identify a list of employment-generating and commercially viable investments for which it could set lower reserve requirements for loans. Other policies, such as the allocation of public investment to priority sectors, should also be utilized. Such sectors can be found across the spectrum of agricultural, manufacturing and service activities.

Boosting manufacturing is a crucial component of such initiatives since it has the potential to create productive and decent-paying employment. Such a manufacturing strategy should rely principally on the growth of medium-sized and large enterprises since, as shown by this study, they are the likeliest to create jobs at 'poverty-reducing' wages. But diversification is needed in agriculture as well. This could involve the substitution of Qat with other agricultural commodities, such as coffee, tobacco, fruits and vegetables, which have strong export potential.

Fishing is a recent example of an agricultural subsector with proven growth potential. The government could help by upgrading infrastructure related to fish handling, storage and transport. It could also encourage greater investment in improved methods of fish farming and in the domestic processing of fish.

Boosting tourism within the service sector is an obvious priority. So is exploiting Yemen's potential in providing port facilities for shipping. Yemen could establish itself as a sea hub, for example, for the Gulf Cooperation Council. In order to lay a sound basis for sustainable growth and employment generation, Yemen needs to diversify its economy as much as possible.

Achieving such diversification will require a comprehensive trade and industrial strategy. This approach would include systematic efforts to promote Yemen's export potential. For example, the country could target specific markets (such as for leather products or handicrafts) and focus on upgrading certain exports (such as natural honey and coffee).

The third prong of Yemen's employment creation strategy involves small-scale interventions that have a poverty reduction focus. This could involve the focusing of public resources on small-scale, labour-intensive public works, such as for rural roads, wells or irrigation works, which can be directed to poorer regions of the country. Such initiatives could also include micro-credit, which should become, in fact, an integral component of the regular financial services of banks, particularly in rural areas. In general, commercial banks will have to be given incentives to expand coverage of their financial services to poorer regions or social groups.

Agriculture is a priority sector for such initiatives. In order to substantially reduce poverty, the Yemeni government should substantially increase public spending on the rural economy. This could take the form of greater investment in public goods, such as storage facilities, 
transportation networks and water preservation technologies. Building up an extensive rural financial system needs to be an integral part of such a strategy.

The increase in infrastructure and financial resources will benefit the rural poor only if they have greater access to vital natural resources such as land and water. Large landholders currently control, for example, much of the access to irrigation. Related to such control, they not only enjoy subsidies but also pay no water taxes. Moreover, access to land has become increasingly unequal, depriving many small farmers of viable means to secure a decent livelihood. An immediate priority is to register ownership of land and document sharecropping use-rights to land.

The fourth prong of Yemen's strategy involves the promotion of a more conducive business environment. Simplifying licensing, fees and taxes are part of this effort. Reducing cumbersome administrative procedures, official harassment and corruption is another important part. Micro and small enterprises often bear the brunt of such practices so reforms in this area will help impart a stimulus to economic growth 'from below'--namely, among the self-employed, micro-entrepreneurs and small enterprises that are struggling to expand and grow. Enabling small enterprises, which are often deprived of resources and public support, to grow rapidly into medium-sized firms - with a potential to provide decent-paying jobs-is a key component of this effort.

A comprehensive growth, employment and poverty reduction strategy for Yemen needs all four of the prongs described above. These recommendations are not designed for a poverty reduction strategy alone. They are geared, first and foremost, to generating more rapid growth and employment, and leveraging this momentum into focused public efforts to reduce poverty. All four prongs are needed for an ambitious MDG-based national development strategy that strives to reach the 2015 targets. At the heart of such a strategy are recommendations to promote broad-based employment generation that is centred in growth sectors that have the potential to pay poverty-reducing, not poverty-reproducing, incomes. 


\section{REFERENCES}

International Labour Organization, Regional Office for the Arab States, Beirut and Employment Strategy Department, Geneva (2004). "A National Employment Agenda for Yemen: Towards an Employment Strategy Framework". Paper for the National Tripartite Symposium on Employment, Sana'a, September 29-30 and October 2, 2004.

Karshenas, Massoud, Khalid Abu-Ismail and Terry McKinley (2006). Macroeconomic Policies for Poverty Reduction: The Case of Yemen, UNDP Regional Bureau for the Arab States and Regional Service Centre, Beirut.

Mehran, Farhad, ILO Bureau of Statistics (2001). "Report on a Mission to Yemen to Analyze the 1999 Labour Force Survey". Draft, October 7.

Mehran, Farhad, Statistical Development and Analysis, Policy Integration Department, ILO (2004a). "An Analysis of the Results of the Labour Demand Survey of Establishments in Yemen, 2002-2003." Draft, August 10.

Mehran, Farhad, Statistical Development and Analysis, Policy Integration Department, ILO (2004b). "Comparing the Measurement of Employment and Unemployment in Three Recent Large Scale Household Surveys in Yemen." Draft prepared for the UNDP Regional Programme in the Arab States on the Macroeconomics of Poverty Reduction, September.

Mehran, Farhad, Statistical Development and Analysis, Policy Integration Department, ILO (2004c). "Key Labour Market Indicators in Yemen." Draft prepared for the UNDP Regional Programme in the Arab States on the Macroeconomics of Poverty Reduction, October.

World Bank (2003). "Unlocking the Employment Potential in the Middle East and North Africa: Towards a New Social Contract." Draft, September, Washington D.C.

World Bank (2004). World Development Indicators. Washington D.C.: World Bank.

\section{NOTE}

1. There is under-reporting of secondary employment in the 1999 Labour Force Survey. Were the hours worked in jobs other than the primary one included, these averages would likely be significantly higher. 
International Poverty Centre SBS - Ed. BNDES, $10^{\circ}$ andar 70076900 Brasilia DF Brazil

povertycentre@undp-povertycentre.org www.undp.org/povertycentre Telephone +55 6121055000 Fax +55 6121055001 